\title{
Patterns of self-medication among medical and nonmedical University students in Jordan
}

This article was published in the following Dove Press journal: Risk Management and Healthcare Policy

\author{
Osama Y Alshogran' \\ Karem H Alzoubi' \\ Omar F Khabour ${ }^{2}$ \\ Shatha Farah ${ }^{2}$ \\ 'Department of Clinical Pharmacy, \\ Faculty of Pharmacy, Jordan University \\ of Science and Technology, Irbid, \\ Jordan; ${ }^{2}$ Department of Medical \\ Laboratory Sciences, Faculty of \\ Applied Medical Sciences, Jordan \\ University of Science and Technology, \\ Irbid, Jordan
}

Background and objective: Self-medication practice involves consumption of medicines by one's own initiative or on the consultation of others without the guidance of a physician. Selfmedication and use of over-the-counter drugs are prevalent worldwide public health concerns. University students of medical and nonmedical disciplines may have different levels of health education. This study evaluated the prevalence and patterns of self-medication and the attitudes toward this practice among medical and nonmedical university students in Jordan.

Methods: A descriptive cross-sectional study was conducted in 504 students (medical: 248 and nonmedical: 256). The students were invited to complete a questionnaire that included questions primarily related to patterns of physician visits, self-medication practice, symptoms provoking self-medication, and sources of advice.

Results: Self-medication was highly prevalent and comparable between medical and nonmedical students ( $96 \%$ ). Headache (81.9\%), cold (58.3\%), and flu (53\%) were the frequent symptoms provoking self-medication among students. Self-medication for headache (86.7\% vs $77.3 \%)$ and tooth pain (53.1\% vs $27 \%$ ) was significantly higher among medical vs nonmedical students, respectively. Self-treatment with painkillers ( $82.3 \%$ vs $73 \%)$ or antiallergy $(11.3 \%$ vs $5.9 \%)$ drugs was significantly higher among medical students, while the use of anti-flu decongestants (47.6\% vs $60.2 \%$ ) was lower compared to nonmedical students, respectively. Nonmedical vs medical students were significantly more dependent on friends (14.8\% vs $7.7 \%)$ and own experience (7.4\% vs $2.4 \%)$ as a source of self-medication advice.

Conclusion: Self-medication is common among Jordanian university students of medical and nonmedical disciplines. This practice, if used irrationally, may constitute a health problem that needs awareness and interventions by health care regulators in Jordan. Future studies are warranted to examine the impact of self-medication on students' health.

Keywords: self-medication, students, medical, nonmedical, survey, Jordan

\section{Introduction}

The US Food And Drug Administration defines over-the-counter (OTC) drugs as "drugs that are safe and effective for use by the general public without seeking treatment by a health professional". ${ }^{1}$ Self-medication is a global form of self-care practice and can be defined as "the taking of drugs, herbs or home remedies on one's own initiative, or on the advice of another person, without consulting a doctor". ${ }^{2}$ Self-medication practice is highly prevalent in the developing countries and can be enhanced by the availability of medicines as OTC. ${ }^{3}$

Self-medication, when adopted correctly, can be more convenient, may relieve acute pain, and reduce treatment cost and physician interaction times. ${ }^{4}$ However, it
Correspondence: Osama Y Alshogran Department of Clinical Pharmacy, Faculty of Pharmacy, Jordan University of Science and Technology, Irbid 221 I0, Jordan

Tel +96227201000

Fax +96227201075

Email oyalshogran@just.edu.jo 
can jeopardize human well-being and result in severe healthrelated complications when implemented inappropriately, such as in cases of self-treatment with prescription-only drugs. ${ }^{5}$ For instance, developing drug resistance is of great concern with the frequent and inappropriate use of antibiotics that could be available without a prescription. A survey conducted over Jordanian households reported that $39.5 \%$ of the participants had used antibiotics without prescription. ${ }^{6}$ Other serious consequences that might be provoked with frequent use of OTC medications include inappropriate dosing, drug duplication, drug interaction, treatment failure, masking of health problems and symptoms, and delay in prescribing the appropriate treatment. ${ }^{7}$

A previous study showed that the reasons behind the prevalent use of OTC medications can include the following: the desire to save money, presence of minor health problems that do not need a visit to the physician, prior experience with drug efficacy, and the long waiting time at physician's clinic or hospitals. ${ }^{8}$ The common sources of self-medications may include families, friends, pharmacists, newspapers, magazines, and Internet websites. ${ }^{9}$

College age group represents an integral part of the community. As medical students usually try to implement their knowledge into practice, self-medication has been frequently assessed among these individuals. The prevalence of selfmedication among university students ranged from 38.5\% in Ethiopia ${ }^{10}$ to $98 \%$ in Palestine. ${ }^{11}$ A meta-analysis of 27 studies of self-medication among physicians and medical students reported self-treatment prevalence of $>50 \%$ in $76 \%$ of the studies. ${ }^{12}$ In Jordan, studies conducted earlier on medication use were focused on medical students ${ }^{13}$ or public, ${ }^{9,14}$ with special attention to the consumption of antimicrobial drugs. ${ }^{6,15,16}$ One study assessed the attitude and behavior of antibiotic use among medical and nonmedical university students and reported high consumption rates regardless of specialty. ${ }^{17}$ As little data are available about self-medication practice among medical and nonmedical students, the goal of this study was to explore the prevalence, attitudes, determinants, and sources of self-medication among Jordanian medical and nonmedical students.

\section{Methods}

This was a descriptive cross-sectional study conducted among a convenient sample of students enrolled at medical and nonmedical schools of Jordan University of Science and Technology (JUST) located at the North of Jordan. The university students' population is about 21,000, of 60 nationalities, distributed at 12 medical and nonmedical schools. Medical schools include pharmacy, medicine, nursing, dentistry, and applied medical sciences. Students of different academic levels (juniors and seniors) were targeted. The students were approached with the survey during their scheduled elective course classes, via taking 10 minutes out of the class time (at the end of the class). The study protocol and obtaining of informed verbal consent were approved by the institutional review board committee at King Abdullah University Hospital, JUST. An informed verbal consent was obtained from individuals after explaining the purpose of the study and that the involvement was voluntary. Students were also informed that their responses would be anonymous and confidential. Graduate students were not included in the study.

The survey included questions about respondents' sociodemographic, clinical information, education, history and pattern of physician visits, students' knowledge and beliefs of OTC medications and practice of the consumption of OTC and prescribed drugs (self-medication), reasons for the self-prescribed practice, sources of advice, and frequent symptoms prompting self-medication. The survey included primarily close-ended questions. Some of the questions may tolerate more than 1 answer (example: reasons for self-medication). Questions were related to the period of the previous 6 months. The questionnaire was also piloted on 50 students and tested among a group of students to receive feedback about understandability and clarity of the questions, and data of the pilot study were not included in the final analysis. The questionnaire was adjusted as per feedback from the piloted sample. The survey was developed after a comprehensive review of the related literature and consultation among the research team. It was face-validated via consultation with expert colleagues in the field and was also objectively validated for comprehensibility and clarity. Reliability was ensured via calculating Cronbach's $\alpha$, which was $>0.7$ for all items of the questionnaire.

Descriptive statistics such as frequency (\%), mean, and SD were used to present participants, characteristics as appropriate. The study questions and characteristics were compared between medical and nonmedical students using independent Student's $t$-test for continuous variables and $\chi^{2}$ test for categorical data. The SPSS software (version 23) (IBM Corporation, Armonk, NY, USA) was used for data analysis at the level of significance of $P<0.05$.

\section{Results}

\section{Demographics and clinical characteristics}

This study was conducted in 504 students, of whom 248 were from medical and 256 were from nonmedical schools. 
Slightly more than half $(55.7 \%)$ of the respondents were female, and the mean age was $21.8 \pm 1.8$ years for all participants $(67.5 \%$ were $\geq 21$ years old $)$. The majority were nonsmokers $(79.6 \%)$ and lived in the city $(67.7 \%)$ in places close to hospitals ( $<25$ minutes driving). When split by study year, the majority were in the third or fourth professional year of their academic study (68\%). Most of the respondents had medical insurance $(83.5 \%)$ and did not have chronic diseases (96\%). The following sociodemographic and clinical characteristics were significantly different between medical and nonmedical students: gender, nationality, age, the area of living, smoking status, college year, monthly income, availability of transport, and medical history. For example, $69.8 \%$ of the medical students were female vs $42.2 \%$ of the nonmedical students, $P<0.001$. Additionally, only $11.1 \%$ of the medical students were smokers vs $25.8 \%$ of the nonmedical students, $P<0.001$. Other participant characteristics are listed in Table 1.

\section{Patterns of medical visits}

Regarding respondents' visits to physicians, $61.4 \%$ of the medical students reported that they had seen physicians at least 1 time in the past 6 months, which was comparable to that of the nonmedical students $(68.6 \%), P=0.154$. The major reasons for visiting physicians among participants were flu (41.5\%), tooth pain (35.1\%), and cold (26.4\%). Nonmedical students had seen physicians for flu (48\%) more than medical students $(34.7 \%), P=0.002$. Both groups of students reported that they highly adhered to doctor instructions. Data about students' medical visits are summarized in Table 2.

\section{Patterns of self-medication}

Significant differences in the knowledge of students about prescription-only or OTC medications were observed (Table 3). Higher percentages of medical students reported that antacids, expectorants, laxatives, antibiotics, and antidiarrhea medications are prescription-only drugs compared to nonmedical. The percentages ranged from $25.4 \%$ to $55.6 \%$ and $18 \%$ to $33.2 \%$ for medical and nonmedical students, respectively. Interestingly, a lower percentage of medical students $(14.5 \%)$ believed that painkillers were prescription-only drugs compared to nonmedical students $(22.7 \%), P=0.019$.

Self-medication was reported by $96.8 \%$ of the participants, and this was not different between medical (97.2\%) and nonmedical students $(96.5 \%)$. The most predominant medicine classes that were self-used by all students in the past 6 months were painkillers $(77.6 \%)$, anti-flu decongestants (54\%), sore throat drugs $(25.9 \%)$, cough suppressants $(24 \%)$, or antibiotics
(21\%). Self-medication was significantly higher in medical compared to nonmedical students with regard to the use of painkillers $(82.3 \%$ vs $73 \%, P=0.013)$ and antiallergy drugs (11.3\% vs $5.9 \%, P=0.029)$. However, the frequency of selfmedication with anti-flu drugs was higher among nonmedical $(60.2 \%)$ vs medical students $(47.6 \%), P=0.005$.

The most common indications for which students take medications on their own were headache $(81.9 \%)$, cold (58.3\%), flu (53\%), and tooth pain (31\%). Medical students showed self-medication practice for headaches and tooth pain significantly more often than nonmedical students (Table 3 ).

\section{Other practices}

The primary sources of advice for taking medications for all students were from physicians $(55.8 \%)$, pharmacists $(52.6 \%)$, Internet websites $(44.2 \%)$, or family members $(36.9 \%)$. A significantly higher frequency of nonmedical compared to medical students was dependent on friends $(14.8 \%$ vs $7.7 \%$, $P=0.011)$ and own experience $(7.4 \%$ vs $2.4 \%, P=0.01)$ as a source of medication use. A significantly higher proportion of medical students (57.1\%) reported that they read medication instructions on the package insert (patient information leaflet) every time they bought a new pack of medication compared to nonmedical students $(53.8 \%), P=0.016$. The majority of participants $(65.3 \%)$ reported that they stopped using the medicine and saw physicians whenever the drug had no effect. These data are listed in Table 4.

\section{Discussion}

This study evaluated patterns and attitudes of medical and nonmedical university students toward self-medication. The study revealed that self-medication practice is very common and comparable between medical and nonmedical students. Students primarily treat themselves to relieve pain and flu symptoms, and nonmedical students are selftreated with anti-flu drugs to a level higher than that of medical students. The study also showed that students are primarily dependent on physicians or pharmacists' advice for self-medication.

The prevalence of self-medication in our cohort sample was $96.8 \%$. This is slightly higher than that reported among Jordanian medical and pharmacy students $(78.5 \%),{ }^{13}$ comparable with health care and non-health care students of Slovenia $(92.3 \%)^{18}$ or Pakistan $(95.5 \%),{ }^{19}$ and much higher than that documented among Saudi medical students $(26 \%)^{20}$ or Egyptian medical and nonmedical students $(62.9 \%) .{ }^{21}$ These differences in self-medication prevalence among students might be explained partially by the variable sample 
Table I Demographics of study participants

\begin{tabular}{|c|c|c|c|c|}
\hline Factor & Total sample (504), N (\%) & Medical (248), N (\%) & Nonmedical (256), N (\%) & $P$-value \\
\hline Gender & & & & $<0.001$ \\
\hline Male & $223(44.3)$ & $75(30.2)$ & I 48 (57.8) & \\
\hline Female & $281(55.7)$ & $173(69.8)$ & $108(42.2)$ & \\
\hline Nationality & & & & $<0.001$ \\
\hline Jordanian & $433(85.9)$ & 191 (77.3) & $242(94.5)$ & \\
\hline Non-Jordanian & $71(14.1)$ & $56(22.7)$ & $14(5.5)$ & \\
\hline Age & $21.8 \pm 1.82$ & $20.77 \pm 1.66$ & $21.57 \pm 1.88$ & $<0.001$ \\
\hline Missing & $5(I)$ & & & \\
\hline Area of living & & & & $<0.001$ \\
\hline City/urban & $34 I(67.7)$ & 191 (77.3) & $150(60.7)$ & \\
\hline Village/rural & $153(30.4)$ & $56(22.7)$ & $97(39.3)$ & \\
\hline Missing & $10(1.9)$ & & & \\
\hline Smoking status & & & & $<0.001$ \\
\hline Smoker & $91(18.1)$ & $27(11.1)$ & $64(25.8)$ & \\
\hline Nonsmoker & $401(79.6)$ & $217(88.9)$ & $184(74.2)$ & \\
\hline Missing & $12(2.3)$ & & & \\
\hline College year & & & & $<0.001$ \\
\hline First & $65(12.9)$ & $49(20.5)$ & $16(6.3)$ & \\
\hline Second & $39(7.7)$ & $17(7.1)$ & $22(8.7)$ & \\
\hline Third & $169(33.5)$ & $115(48.1)$ & $54(21.3)$ & \\
\hline Fourth & $174(34.5)$ & $44(18.4)$ & $130(5 \mid .4)$ & \\
\hline Fifth or sixth & $45(8.9)$ & $14(5.9)$ & $31(12.3)$ & \\
\hline Missing & $12(2.3)$ & & & \\
\hline Monthly income (JDs) & & & & $<0.001$ \\
\hline$<400$ & $117(23.2)$ & $4 \mid(17)$ & $76(30.4)$ & \\
\hline $400-1,000$ & $243(48.2)$ & $118(49)$ & $125(50)$ & \\
\hline$>1,000$ & $|3|(26.0)$ & $82(34)$ & $49(19.6)$ & \\
\hline Missing & $13(2.6)$ & & & \\
\hline Insurance & & & & 0.072 \\
\hline Available & $421(83.5)$ & $214(87.3)$ & 207 (8I.5) & \\
\hline Not available & $78(15.5)$ & $31(12.7)$ & $47(18.5)$ & \\
\hline Missing & $5(1)$ & & & \\
\hline Nearness to hospitals & & & & 0.376 \\
\hline $5-25$ minutes away & $406(80.6)$ & $202(82.8)$ & $204(80)$ & \\
\hline $25-60$ minutes away & $70(13.9)$ & 34 (13.9) & $36(14.1)$ & \\
\hline$>60$ minutes away & $23(4.5)$ & $8(3.3)$ & $15(5.9)$ & \\
\hline Missing & $5(1)$ & & & \\
\hline \multicolumn{5}{|c|}{ Availability of public or private transport } \\
\hline Available & $479(95)$ & $243(98.8)$ & $236(92.9)$ & 0.001 \\
\hline Not available & $21(4.2)$ & $3(1.2)$ & $18(7.1)$ & \\
\hline Missing & $4(0.8)$ & & & \\
\hline Medical history & & & & 0.031 \\
\hline Yes & $17(3.4)$ & $4(1.6)$ & $13(5.1)$ & \\
\hline No & $484(96)$ & $243(98.4)$ & $241(94.9)$ & \\
\hline Missing & $3(0.6)$ & & & \\
\hline
\end{tabular}

size or the level of medical knowledge and the responsible self-medication between students.

Self-medication among students was also higher compared to the Jordanian public $(42.5 \%) .{ }^{9}$ This could be attributed to the higher level of medical and pharmaceutical knowledge about medications and their uses among university students; thus, it is likely that this knowledge is sufficient to practice self-treatment. The high level of self-medication observed among students of nonmedical disciplines indicates that students are becoming more familiar with medicines and their uses and that may be attributed partially to the large willingness to know and learn about medications from newspapers and Internet websites or even from the social networks. In fact, we showed that nonmedical students were more dependent on friends and own experience as a source of advice for self-medication, suggesting that they were 
Table 2 Patterns of medical visits among students

\begin{tabular}{|c|c|c|c|}
\hline Factor & $\begin{array}{l}\text { Medical, } \\
\text { N (\%) }\end{array}$ & $\begin{array}{l}\text { Nonmedical, } \\
\text { N (\%) }\end{array}$ & $P$-value \\
\hline Number of physician's visits & & & 0.154 \\
\hline \multicolumn{4}{|l|}{ within the previous 6 months } \\
\hline More than once per month & $16(6.5)$ & $23(9.1)$ & \\
\hline Once per month & $35(14.2)$ & $49(19.4)$ & \\
\hline More than once & 49 (19.9) & $59(23.3)$ & \\
\hline Once & $51(20.7)$ & $45(17.8)$ & \\
\hline None & $95(38.6)$ & $77(30.4)$ & \\
\hline \multicolumn{4}{|l|}{ Reasons for physician's visits } \\
\hline Headaches & $44(17.7)$ & $49(19.1)$ & 0.686 \\
\hline Flu & $86(34.7)$ & $123(48)$ & 0.002 \\
\hline Cold & $66(26.6)$ & $67(26.2)$ & 0.911 \\
\hline Cough & $25(10.1)$ & $22(8.6)$ & 0.566 \\
\hline Insomnia & II (4.4) & $10(3.9)$ & 0.766 \\
\hline Acne/skin disease & $41(16.5)$ & $33(12.9)$ & 0.248 \\
\hline Tooth pain & $90(36.3)$ & $87(34)$ & 0.588 \\
\hline Stomach pain/heartburn & $23(9.3)$ & $25(9.8)$ & 0.851 \\
\hline $\begin{array}{l}\text { Disorder of digestive } \\
\text { system (diarrhea, vomiting, } \\
\text { constipation) }\end{array}$ & $21(8.5)$ & $15(5.9)$ & 0.256 \\
\hline Hemorrhoids & $4(1.9)$ & $5(2)$ & 0.773 \\
\hline Infections & $25(10.1)$ & $27(10.5)$ & 0.863 \\
\hline Allergy & $40(16.1)$ & $32(12.5)$ & 0.244 \\
\hline Menstrual problems ${ }^{a}$ & $17(9.8)$ & $9(8.3)$ & 0.674 \\
\hline Others & $31(12.5)$ & $35(13.7)$ & 0.697 \\
\hline $\begin{array}{l}\text { After your office visit, do } \\
\text { you follow your physician's }\end{array}$ & & & 0.558 \\
\hline \multicolumn{4}{|l|}{ instructions? } \\
\hline Yes & $205(88.7)$ & $207(87)$ & \\
\hline No & $26(11.3)$ & $31(13)$ & \\
\hline
\end{tabular}

Notes: a Females only. Bold text indicates $P<0.05$ which is statistically significant.

more prone to accept recommendations from their friends compared to medical students. In Egypt, a study showed that neighbors and family, own decision, and Internet were frequent resources for self-medication among students. ${ }^{21}$ Another study reported that friends and family, chemist, and Internet were the primary 3 resources of self-medication among undergraduate students of Nepal. ${ }^{22}$ Other explanations for the high prevalence of self-medication in this study may include convenience, lack of time to seek physician appointment, and the fact that around $16 \%$ of the study cohort were not medically insured.

Consistent with a former study, ${ }^{23}$ painkillers including analgesics/antipyretics were the most commonly used medications among students. For example, analgesics (55.4\%) were the most frequently self-treated medications in a sample of 1,296 medical students in Serbia. ${ }^{23}$ The nonsignificant difference in the prevalence of self-medication observed between medical and nonmedical students is in accordance with other investigations. ${ }^{7,19}$ Nevertheless, medical and nonmedical students showed significant differences in their practice of self-medication with some group of drugs. While medical students used painkillers and antiallergy drugs more than nonmedical students, they showed lower usage of antiflu decongestants. Perhaps, the medical knowledge gained in college might act as a driving factor for medical students to make decisions of self-medication, even with drugs that might sometimes require a prescription such as antiallergy drugs. Additionally, medical students may feel that their scientific knowledge is solid and they may no longer need medical consultation. ${ }^{13}$ The higher self-medication with anti-flu drugs in the nonmedical students might be related to their previous experience with the disease and such OTC medications. However, this frequent use of anti-flu decongestants may have not been effective as nonmedical students reported that they had commonly seen physicians for flu symptoms, and this was at a percentage higher than that of medical students. Although the use of antibiotics was not different between the student groups, its frequent use $(21 \%)$ is of concern. As reported earlier, this inappropriate use of antibiotics may delay the prescribing of proper treatment and may increase the likelihood of bacterial resistance. ${ }^{6,15}$

In agreement with previous studies, ${ }^{7,21}$ we found that headache, cold, and flu were the predominant health problems that provoked self-medication practice. For instance, a study conducted among 572 students in Pakistan found that students were primarily self-medicated for symptoms of headache (72.4\%), flu (65.5\%), and fever (55.2\%). ${ }^{7}$ Moreover, studies found that being a medical student was a significant risk factor for self-medication, ${ }^{21,24}$ and this was reflected in this study as it showed that medical students self-treated for headaches and tooth pain significantly higher than nonmedical students.

The widespread use of self-medication, especially for prescription-only drugs such as antibiotics, is of concern. ${ }^{6,25}$ Consistently, a study conducted among 731 Chinese students reported that $40.2 \%$ of the students self-treated with antibiotics purchased without a prescription from retail pharmacies and that they used this frequently for common colds. ${ }^{26}$ The dispensing of antibiotics has to be restricted and regulated on different levels including legislations, physicians' prescribing, pharmacy dispensing, and awareness of the population. Thus, implementing legal regulations should be encouraged among community pharmacies, which have to adhere to laws and policies concerning good dispensing practice to limit the misuse and irrational use of medicine. As this study was not designed to assess the appropriateness of self-medication, future investigations are required to evaluate the positive and negative impacts of self-medication on students' health. 
Table 3 Patterns of self-medication among students

\begin{tabular}{|c|c|c|c|}
\hline Factor & Medical, N (\%) & Nonmedical, $\mathbf{N}(\%)$ & $P$-value \\
\hline \multicolumn{4}{|l|}{ In your opinion, which of the following are prescription-only drugs? } \\
\hline Pain killers & $36(14.5)$ & $58(22.7)$ & 0.019 \\
\hline Cough suppressants & $46(18.5)$ & $37(14.5)$ & 0.215 \\
\hline Antacids & $47(29.8)$ & $53(20.7)$ & 0.018 \\
\hline Antiallergy & $136(54.8)$ & $121(47.5)$ & 0.097 \\
\hline Anti-cold/flu & $54(21.8)$ & $48(18.8)$ & 0.398 \\
\hline Expectorants & $63(25.4)$ & $46(18)$ & 0.043 \\
\hline Laxatives & $81(32.7)$ & $57(22.3)$ & 0.009 \\
\hline Skin treatment drug & $160(64.5)$ & I5I (59) & 0.202 \\
\hline Drugs used for sore throat & $52(2 I)$ & $46(18)$ & 0.395 \\
\hline Antibiotic & $138(55.6)$ & $85(33.2)$ & $<0.001$ \\
\hline Antidiarrhea & $89(35.9)$ & $63(24.6)$ & 0.006 \\
\hline \multicolumn{4}{|c|}{ Which of the following drugs have you taken without prescription for the last 6 months? } \\
\hline Painkillers & $204(82.3)$ & $187(73)$ & 0.013 \\
\hline Anti-cough drug & $52(2 I)$ & $69(27)$ & 0.116 \\
\hline Antiacidity drug & $34(13.7)$ & $38(14.8)$ & 0.716 \\
\hline Antiallergy drug & $28(11.3)$ & $15(5.9)$ & 0.029 \\
\hline Anti-flu drug (decongestants) & $118(47.6)$ & $154(60.2)$ & 0.005 \\
\hline Expectorants & $16(3.2)$ & $15(3.0)$ & 0.782 \\
\hline Laxatives & $8(3.2)$ & $5(2)$ & 0.368 \\
\hline Skin treatment drug & $13(5.2)$ & $15(5.9)$ & 0.754 \\
\hline Sore throat drug & $70(28.2)$ & $60(23.4)$ & 0.219 \\
\hline Antibiotic & $54(21.8)$ & $52(20.3)$ & 0.687 \\
\hline Antidiarrhea & $7(2.8)$ & $10(3.9)$ & 0.5 \\
\hline \multicolumn{4}{|c|}{ For which of the following indications have you taken medications without prescription for the last 6 months? } \\
\hline Headaches & $215(86.7)$ & $198(77.3)$ & 0.006 \\
\hline Flu & $126(50.0)$ & $|4|(55.1)$ & 0.337 \\
\hline Cold & $140(56.5)$ & $154(60.4)$ & 0.37 \\
\hline Cough & $42(16,9)$ & $47(18.4)$ & 0.675 \\
\hline Insomnia & $20(8.1)$ & $21(8.2)$ & 0.955 \\
\hline Acne/skin disease & $21(8.5)$ & $21(8.2)$ & 0.914 \\
\hline Tooth pain & $87(53.1)$ & $69(27)$ & 0.048 \\
\hline Stomach pain/heartburn & $54(21.8)$ & $59(23)$ & 0.732 \\
\hline Disorder of digestive system (diarrhea, vomiting, constipation, etc) & $25(10.1)$ & $25(9.8)$ & 0.906 \\
\hline Hemorrhoids & $2(0.8)$ & $2(0.8)$ & 0.975 \\
\hline Infection & $14(5.6)$ & $22(8.6)$ & 0.199 \\
\hline Allergy & $26(10.5)$ & $25(9.8)$ & 0.778 \\
\hline Menstrual problems ${ }^{a}$ & $81(46.8)$ & $48(44.4)$ & 0.697 \\
\hline
\end{tabular}

Notes: a Females only. Bold text indicates $P<0.05$ which is statistically significant.

Although self-medication practice was high among students, they showed some awareness about the use of medications. For instance, nearly half of our participants reported that they read medication instructions every time they bought a new pack of medicine, an attitude that was unsurprisingly more prevalent with medical students. In addition, students were willing to see physicians whenever the medicine is not working for them. Nevertheless, awareness and knowledge about self-medication and its good and bad consequences have to be enhanced among university students. Medication and health awareness campaigns and educational sessions in the university campus may be appropriate.
This study is the first to comprehensively compare the pattern of self-medication between medical and nonmedical students in Jordan. However, there are some limitations. The study was conducted at 1 large university in the North of Jordan although there are other universities that include medical and nonmedical disciplines in other parts of the country. The survey was self-reported, and this may have contributed to the inconsistent understanding of questions between students. A recall bias is possible as students were asked about their experience in the past 6 months. Although the sample size may be relatively small, it is convenient and the results can reflect the pattern of self-medication among 
Table 4 Characteristics of medication use

\begin{tabular}{|c|c|c|c|}
\hline Factor & Medical, N (\%) & Nonmedical, N (\%) & $P$-value \\
\hline \multicolumn{4}{|l|}{ When taking medications, whose advice do you follow? } \\
\hline Physician & I48 (59.7) & $133(52)$ & $0.08 \mathrm{I}$ \\
\hline Pharmacist & $133(53.6)$ & $132(5 \mid .8)$ & 0.675 \\
\hline Other medical members (ie, nurses) & $9(3.6)$ & $6(2.3)$ & 0.396 \\
\hline Family members & $82(33.1)$ & $104(40.6)$ & 0.079 \\
\hline Friends & $19(7.7)$ & $38(14.8)$ & 0.011 \\
\hline Advertisement on TV or newspaper & $30(12.1)$ & $26(10.2)$ & 0.488 \\
\hline Own experience & $6(2.4)$ & $19(7.4)$ & 0.01 \\
\hline Internet medical websites & $114(46)$ & $109(42.6)$ & 0.444 \\
\hline When do you take these medications? & & & 0.134 \\
\hline When there are symptoms & $70(29.7)$ & $96(38.7)$ & \\
\hline When the symptoms are moderate and sustain for more than 3 days & $97(4 I .1)$ & $96(38.7)$ & \\
\hline When the symptoms are increasing in severity & $66(28)$ & $52(21)$ & \\
\hline Before symptoms to prevent against disease & $3(1.3)$ & $4(1.6)$ & \\
\hline Others & $8(3.2)$ & $5(2)$ & \\
\hline Do you read medication instructions sheet? & & & 0.016 \\
\hline Yes, every time I buy a new pack & I4I (57.I) & $136(53.8)$ & \\
\hline Yes, when I buy a medication for the first time & $82(33.2)$ & $69(27.3)$ & \\
\hline Yes, only when side effects appear & $6(2.4)$ & $20(4.7)$ & \\
\hline No, I do not & $14(5.7)$ & $34(13.4)$ & \\
\hline Others & $4(1.6)$ & $2(0.8)$ & \\
\hline When a medication has no effect, what do you do? & & & 0.133 \\
\hline Stop taking the medicine and see the physician & $169(68.7)$ & $160(64.5)$ & \\
\hline Stop taking the medicine and consult the pharmacist & $12(4.9)$ & $27(10.9)$ & \\
\hline I would increase the dose on my own & $98(7.7)$ & $17(6.9)$ & \\
\hline I would decrease the dose on my own & $40(16.3)$ & $35(14.1)$ & \\
\hline Others & $6(2.4)$ & $9(3.6)$ & \\
\hline
\end{tabular}

Note: Bold text indicates $P<0.05$ which is statistically significant.

university students. Also, there were multiple demographic factors that were significantly different between the 2 groups, which may have impacted the differences in students' patterns and practices with regard to self-medication.

\section{Conclusion}

Self-medication practice is high among medical and nonmedical university students for OTC or prescription-only medications. Although the prevalence is similar among medical and nonmedical students, some differences with respect to medical indications and the type of drugs utilized were observed between students. Health professionals have to improve students' awareness about consumption of prescription-only drugs such as antibiotics and its health consequences. The dispensing of medicine has to be controlled by Jordanian health care authorities through developing effective preventative and interventional strategies; thus, an appropriate use of medications is achieved.

\section{Acknowledgment}

We would like to thank all participants of the study. This research received no specific grant from any funding agency in the public, commercial, or not-for-profit sectors.

\section{Disclosure}

The authors report no conflicts of interest in this work.

\section{References}

1. US Food and Drug Administration. Drug Applications for Overthe-Counter (OTC) Drugs. Silver Spring, MD: US Food and Drug Administration. Available from: https://www.fda.gov/drugs/developmentapprovalprocess/howdrugsaredevelopedandapproved/approvalapplications/over-the-counterdrugs/default.htm. Accessed March 23, 2018.

2. Hernandez-Juyol M, Job-Quesada JR. Dentistry and self-medication: a current challenge. Med Oral. 2002;7(5):344-347.

3. Shehnaz SI, Agarwal AK, Khan N. A systematic review of self-medication practices among adolescents. $J$ Adolesc Health. 2014;55(4): $467-483$.

4. James H, Handu SS, Al Khaja KA, Otoom S, Sequeira RP. Evaluation of the knowledge, attitude and practice of self-medication among first-year medical students. Med Princ Pract. 2006;15(4): 270-275.

5. Hughes CM, Mcelnay JC, Fleming GF. Benefits and risks of self medication. Drug Saf. 2001;24(14):1027-1037.

6. Al-Azzam SI, Al-Husein BA, Alzoubi F, Masadeh MM, Al-Horani MA. Self-medication with antibiotics in Jordanian population. Int J Occup Med Environ Health. 2007;20(4):373-380.

7. Zafar SN, Syed R, Waqar S, et al. Self-medication amongst university students of Karachi: prevalence, knowledge and attitudes. $J$ Pak Med Assoc. 2008;58(4):214-217.

8. Osemene KP, Lamikanra A. A Study of the prevalence of self-medication practice among university students in southwestern Nigeria. Trop $J$ Pharm Res. 2012;11(4):683-689. 
9. Yousef AM, Al-Bakri AG, Bustanji Y, Wazaify M. Self-medication patterns in Amman, Jordan. Pharm World Sci. 2008;30(1):24-30.

10. Abay SM, Amelo W. Assessment of self-medication practices among medical, pharmacy, and health science students in Gondar University, Ethiopia. J Young Pharm. 2010;2(3):306-310.

11. Sawalha AF. A descriptive study of self-medication practices among Palestinian medical and nonmedical university students. Res Social Adm Pharm. 2008;4(2):164-172.

12. Montgomery AJ, Bradley C, Rochfort A, Panagopoulou E. A review of self-medication in physicians and medical students. Occup Med. 2011;61(7):490-497.

13. Alkhatatbeh MJ, Alefan Q, Alqudah MA. High prevalence of selfmedication practices among medical and pharmacy students: a study from Jordan. Int J Clin Pharmacol Ther. 2016;54(5):390-398.

14. Haddad M, Ebada ME. Demographic and socioeconomic characteristics of outpatients could modify their attitude towards misusing medications in Northern Jordan. J Public Health Res. 2017;6(1):818.

15. Al-Bakri AG, Bustanji Y, Yousef AM. Community consumption of antibacterial drugs within the Jordanian population: sources, patterns and appropriateness. Int J Antimicrob Agents. 2005;26(5):389-395.

16. Shehadeh M, Suaifan G, Darwish RM, Wazaify M, Zaru L, Alja'fari S. Knowledge, attitudes and behavior regarding antibiotics use and misuse among adults in the community of Jordan. A pilot study. Saudi Pharm J. 2012;20(2):125-133.

17. Suaifan G, Shehadeh M, Darwish D, Al-Ijel H, Yousef A-MM. Darwish R. A cross-sectional study on knowledge, attitude and behavior related to antibiotic use and resistance among medical and non-medical university students in Jordan. Afr J Pharm Pharmacol. 2012;6(10): 763-770.
18. Klemenc-Ketis Z, Hladnik Z, Kersnik J. Self-medication among healthcare and non-healthcare students at University of Ljubljana, Slovenia. Med Princ Pract. 2010;19(5):395-401.

19. Ullah H, Khan SA, Ali S, et al. Evaluation of self-medication amongst university students in Abbottabad, Pakistan; prevalence, attitude and causes. Acta Pol Pharm. 2013;70(5):919-922.

20. Albusalih FA, Naqvi AA, Ahmad R, Ahmad N. Prevalence of selfmedication among students of pharmacy and medicine colleges of a public sector university in Dammam City, Saudi Arabia. Pharmacy. 2017;5(3):E51.

21. Helal RM, Abou-Elwafa HS. Self-medication in university students from the city of Mansoura, Egypt. J Environ Public Health. 2017;2017: 9145193.

22. Bhattarai N, Basyal D, Bhattarai N. Self medication practice among undergraduate pharmacy students in Kathmandu Valley, Nepal. Int $J$ Pharm Sci Res. 2014;5(11):737-746.

23. Lukovic JA, Miletic V, Pekmezovic T, et al. Self-medication practices and risk factors for self-medication among medical students in Belgrade, Serbia. PLoS One. 2014;9(12):e114644.

24. Corrêa da Silva MG, Soares MC, Muccillo-Baisch AL. Self-medication in university students from the city of Rio Grande, Brazil. BMC Public Health. 2012;12:339.

25. Ghaieth MF, Elhag SR, Hussien ME, Konozy EH. Antibiotics selfmedication among medical and nonmedical students at two prominent Universities in Benghazi City, Libya. J Pharm Bioallied Sci. 2015;7(2):109-115.

26. Lv B, Zhou Z, Xu G, et al. Knowledge, attitudes and practices concerning self-medication with antibiotics among university students in western China. Trop Med Int Health. 2014;19(7):769-779.
Risk Management and Healthcare Policy

\section{Publish your work in this journal}

Risk Management and Healthcare Policy is an international, peer-reviewed, open access journal focusing on all aspects of public health, policy, and preventative measures to promote good health and improve morbidity and mortality in the population. The journal welcomes submitted papers covering original research, basic science, clinical and epidemiological

\section{Dovepress}

studies, reviews and evaluations, guidelines, expert opinion and commentary, case reports and extended reports. The manuscript management system is completely online and includes a very quick and fair peerreview system, which is all easy to use. Visit http://www.dovepress.com/ testimonials.php to read real quotes from published authors. 